\title{
Which thiazide to choose as add-on therapy for hypertension?
}

\author{
This article was published in the following Dove Press journal: \\ Integrated Blood Pressure Control \\ 30 July 2014 \\ Number of times this article has been viewed
}

\author{
Vivencio Barrios' \\ Carlos Escobar ${ }^{2}$ \\ 'Department of Cardiology, \\ Hospital Ramon y Cajal, \\ ${ }^{2}$ Department of Cardiology, \\ Hospital La Paz, Madrid, Spain
}

Correspondence: Vivencio Barrios Department of Cardiology, Hospital Ramon y Cajal, Carretera Colmenar km 9, I00, 28034 Madrid, Spain

Tel +34913368259

Fax +34913368 665

Email vbarrios.hrc@salud.madrid.org

\begin{abstract}
Combined therapy is required in the majority of patients with hypertension to achieve blood pressure (BP) targets. Although different antihypertensive drugs can be combined, not all combinations are equally effective and safe. In this context, the combination of a renin angiotensin system inhibitor with a diuretic, usually a thiazide, particularly hydrochlorothiazide (HCTZ) or thiazide-like diuretics, such as chlorthalidone or indapamide, is recommended. However, not all diuretics are equal. Although HCTZ, chlorthalidone, and indapamide as add-on therapy effectively reduce BP levels, the majority of studies have obtained greater BP reductions with chlorthalidone or indapamide than with HCTZ. Moreover, there are data showing benefits with chlorthalidone or indapamide beyond BP. Thus, chlorthalidone seems to have pleiotropic effects beyond BP reduction. Moreover, compared with placebo, chlorthalidone has small effects on fasting glucose and total cholesterol, and compared with HCTZ, chlorthalidone achieves significantly lower total cholesterol and low-density lipoprotein cholesterol levels. Similarly, indapamide has demonstrated no negative impact on glucose or lipid metabolism. More importantly, although head-to-head clinical trials comparing the effects of indapamide or chlorthalidone with HCTZ are not available, indirect comparisons and post hoc analyses suggest that the use of chlorthalidone or indapamide is associated with a reduction in cardiovascular events. Despite this, the most frequent diuretic used in clinical practice as add-on therapy for hypertension is HCTZ. The purpose of this review is to update the published data on the efficacy and safety of HCTZ, chlorthalidone, and indapamide as add-on therapy in patients with hypertension.
\end{abstract}

Keywords: blood pressure control, hydrochlorothiazide, thiazide-like diuretics, chlorthalidone, indapamide, combined therapy

\section{Importance of blood pressure control}

Hypertension is one of the most important risk factors for the development of cardiovascular disease, including stroke, ischemic heart disease, heart failure, and chronic kidney disease. ${ }^{1}$ Approximately $54 \%$ of stroke, $47 \%$ of ischemic heart disease, and $13.5 \%$ of total deaths are attributable to hypertension worldwide. ${ }^{2}$ This is very relevant, given that more than one third of adults have hypertension. ${ }^{3}$ Noteworthy is that although these numbers increase markedly with age, hypertension has become increasingly common in the younger age groups in recent years. ${ }^{4}$

Decreasing blood pressure (BP) levels to recommended targets is essential to improve the cardiovascular prognosis in the hypertensive population. The reduction of coronary heart disease mortality observed in a number of countries has been at least in part associated with improved medical treatment and control of risk factors, particularly with regard to systolic BP and total cholesterol. ${ }^{5,6}$ Data from INVEST 
(the INternational VErapamil SR-Trandolapril STudy) showed that hypertensive patients with ischemic heart disease and a higher proportion of visits in which BP control was attained had a $32 \%$ reduction in the risk of myocardial infarction and a $50 \%$ reduction in the risk of stroke. ${ }^{7}$

In recent years, there has been an improvement in BP control rates worldwide. ${ }^{8-12}$ This improvement has been attributed mainly to increased use of antihypertensive agents, particularly combined therapy. ${ }^{13}$

\section{Importance of combined therapy in the treatment of hypertension}

It has been reported that most patients with hypertension need at least two antihypertensive agents to achieve BP goals, particularly patients at higher risk. ${ }^{14,15}$ Combining antihypertensive drugs with different mechanisms of action is a logical approach, because hypertension is caused by multifactorial interacting mechanisms. ${ }^{15}$ As a result, the combination of drugs with different mechanisms of action can enhance the antihypertensive efficacy of each agent in monotherapy when combined, and may block counter-regulatory mechanisms, thereby reducing the incidence of side effects. ${ }^{15}$ Current guidelines recommend the use of combined therapy when monotherapy fails to attain BP goals, and as a first choice in patients with markedly elevated BP, particularly those at high or very high cardiovascular risk. ${ }^{16,17}$

Although different antihypertensive drugs can be combined, not all combinations are equally effective and safe. In this context, the combination of a renin angiotensin system inhibitor (either an angiotensin-converting enzyme inhibitor [ACEi] or an angiotensin receptor blocker [ARB]) with a diuretic, usually a thiazide or thiazide-like agent, is specifically recommended. ${ }^{16,17}$ In fact, both types of drugs have synergistic mechanisms of action. The thiazides enhance the activity of the renin angiotensin system, increasing the efficacy of renin angiotensin system inhibitors. Moreover, ACEi and ARB reduce the risk of the side effects associated with diuretics, including hypokalemia and metabolic disturbances (ie, hyperglycemia, insulin resistance, and hyperuricemia). ${ }^{18-21}$ The combination of a renin angiotensin system inhibitor and a diuretic is very common in clinical practice. Thus, in Spain, when combined therapy is required, the combination preferred by general practitioners for most patients is a renin angiotensin system blocker and a diuretic. $^{12}$

Hydrochlorothiazide (HCTZ), chlorthalidone, and indapamide have been diuretics the most frequently used in combination with an ACEi or ARB. However, in clinical practice, the majority of fixed combinations containing a renin angiotensin system inhibitor and a diuretic have included HCTZ. ${ }^{12,14}$ Are there differences between these diuretics? The aim of this review was to analyze the available evidence regarding the efficacy and safety of these drugs alone and as add-on therapy in patients already taking agents that block the renin angiotensin system.

\section{Pharmacokinetics of hydrochlorothiazide, chlorthalidone, and indapamide}

HCTZ is a thiazide that is rapidly absorbed after oral intake and reaches peak concentrations in about 2 hours. It has been calculated that the half-life of HCTZ is approximately 8-15 hours with long-term dosing. It is eliminated unchanged in the urine. Different studies have shown that the pharmacodynamic response of HCTZ is much longer than expected from its half-life, supporting once-daily dosing of this drug. On the other hand, it has been reported that doses higher than $25 \mathrm{mg}$ do not markedly increase the antihypertensive efficacy of HCTZ, but are associated with a higher risk of hypokalemia. In contrast, HCTZ doses of $12.5 \mathrm{mg}$ daily, despite being less effective than $25 \mathrm{mg}$ daily, cause less hypokalemia. ${ }^{22-28}$

Chlorthalidone is a thiazide-like diuretic. After oral intake, peak serum concentrations are achieved in 2-6 hours. The half-life of chlorthalidone is approximately 42 (range 29-55) hours, reaching 45-60 hours after longterm dosing. However, interindividual variability in the half-life of chlorthalidone is wide. Chlorthalidone is excreted unchanged by the kidneys. The natriuretic effect of chlorthalidone is maximal at 18 hours and lasts more than 48 hours. Comparing different doses of chlorthalidone, it has been observed that $25 \mathrm{mg}$ daily is nearly as effective as higher doses, but with less risk of hypokalemia. Other studies have shown that chlorthalidone doses of $12.5 \mathrm{mg}$ and $25 \mathrm{mg}$ daily offer the best efficacy and safety (in terms of hypokalemia) profiles. $^{22,29,30}$

Indapamide is a thiazide-like diuretic agent acting in the proximal segment of the distal tubule, mainly on sodium and chloride excretion and with a lesser effect on potassium or uric acid urine excretion. Indapamide reduces vascular reactivity to pressor amines. It is rapidly absorbed after oral ingestion and is metabolized predominantly in the liver, mainly by cytochrome P450 (CYP)2C9 and CYP3A4 isozymes and by cytosolic hydrolysis enzymes. The plasma elimination half-life is biphasic (14 and 25 hours), and the main route of elimination is via the urine..$^{21,31,32}$ 


\section{Efficacy and safety of HCTZ as add-on therapy}

The addition of HCTZ to an ACEi or ARB as a free or fixed combination has been widely investigated and used in clinical practice. In one study, patients with uncontrolled BP despite treatment with HCTZ $25 \mathrm{mg}$ daily were randomized to receive amiloride $2.5-5 \mathrm{mg}$ /day or enalapril $10-20 \mathrm{mg}$ /day. After 12 weeks of treatment, the addition of enalapril was more effective than amiloride for lowering BP, as measured by ambulatory BP monitoring and office systolic BP. ${ }^{33}$

INCLUSIVE (Irbesartan/HCTZ Blood Pressure Reductions in Diverse Patient Populations) was a multicenter, prospective, open-label, single-arm study that aimed to determine the efficacy and safety of a fixed combination of irbesartan and HCTZ in patients with uncontrolled systolic BP after at least 4 weeks of antihypertensive monotherapy. Treatment was sequential, ie, placebo (4-5 weeks), HCTZ $12.5 \mathrm{mg}$ (2 weeks), irbesartan/HCTZ 150/12.5 mg (8 weeks), and irbesartan/HCTZ 300/25 mg ( 8 weeks). At the end of the study, more than $75 \%$ of patients who had been uncontrolled on monotherapy achieved their target systolic BP. All the treatments were well tolerated. ${ }^{34}$

A number of studies have analyzed the efficacy of combining candesartan with HCTZ. ${ }^{35-38}$ In a dose-response analysis of a combination of candesartan $(2-32 \mathrm{mg})$ and HCTZ (6.25-25 mg) performed in 4,632 patients with mild to moderate hypertension, the effects of this combination were dose-related over a wide range of doses and additive. ${ }^{35}$

In the OLMEBEST study, the question of whether dose titration of olmesartan medoxomil (to $40 \mathrm{mg}$ once daily) and olmesartan medoxomil/HCTZ combination therapy (to $20 / 12.5 \mathrm{mg}$ once daily) was therapeutically equivalent was investigated in 2,306 patients with mild to moderate hypertension that was not controlled on low-dose olmesartan medoxomil monotherapy (20 mg once daily). At the end of the study, both strategies were effective and well tolerated. ${ }^{39}$

\section{Efficacy and safety of chlorthalidone}

Several studies have analyzed the effects of chlorthalidone on reduction of BP levels and on cardiovascular outcomes. Azilsartan medoxomil is the most recent ARB to reach the market. It is currently available as monotherapy or as a fixeddose combination with chlorthalidone. In a double-blind factorial study, the efficacy and safety of a fixed-dose combination of azilsartan medoxomil and chlorthalidone were compared with those of its individual components in 1,714 patients with a clinic systolic BP of 160-190 mmHg. Patients were randomized to treatment with azilsartan $0 \mathrm{mg}, 20 \mathrm{mg}, 40 \mathrm{mg}$, or $80 \mathrm{mg}$ and/or chlorthalidone $0 \mathrm{mg}, 12.5 \mathrm{mg}$, or $25 \mathrm{mg}$. After 8 weeks of follow-up, combination treatment with azilsartan and chlorthalidone resulted in a substantially greater reduction in systolic BP than that achieved with either drug alone. ${ }^{40}$ Improvement in BP control using chlorthalidone has been associated with a regression of left ventricular hypertrophy. ${ }^{41}$

The SHEP (Systolic Hypertension in the Elderly Program) study was performed to assess the ability of antihypertensive drug treatment to reduce the risk of stroke in 4,736 patients $\geq 60$ years with isolated systolic hypertension. The risk of stroke was reduced by $36 \%$ using stepped-care antihypertensive treatment, with low-dose chlorthalidone as the step 1 medication (Figure 1). ${ }^{42}$ Moreover, in the SHEP study, low-dose chlorthalidone effectively reduced the risk of cardiovascular events, including cerebrovascular and cardiac events, regardless of the presence of diabetes. ${ }^{43}$ Additionally, stepped-care treatment based on low-dose chlorthalidone had a strong protective effect with regard to prevention of heart failure, particularly in patients with a previous history of myocardial infarction. ${ }^{44}$ The effects of active treatment in the participants randomized to active therapy in SHEP were specifically analyzed after a 22-year follow-up, and it was found that stepped-care chlorthalidone therapy for 4.5 years was associated with a longer life expectancy. ${ }^{45}$

In a prespecified subgroup analysis of 15,638 women and 17,719 men who participated in ALLHAT (the Antihypertensive and Lipid-Lowering Treatment to Prevent Heart Attack Trial), with a total follow-up of 8-13 years (active treatment plus passive surveillance using national administrative databases to ascertain deaths and hospitalizations), the risk of the primary coronary

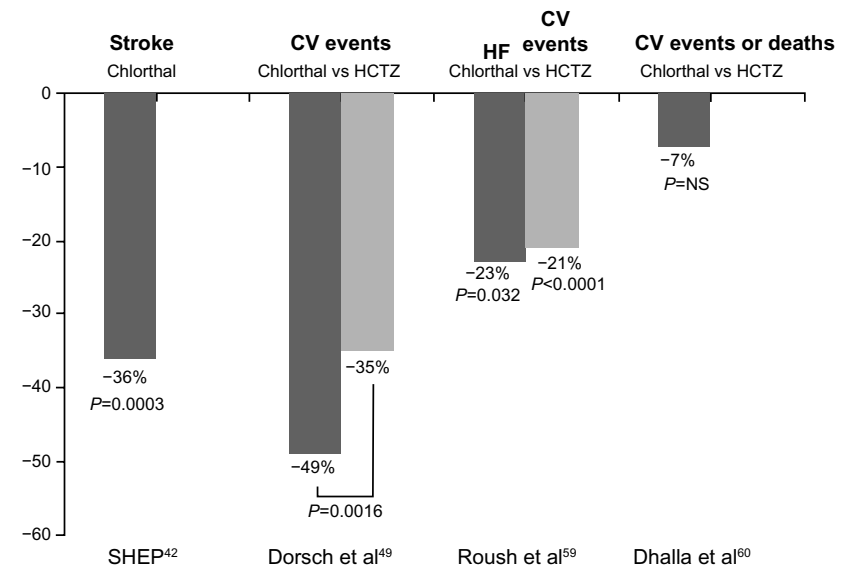

Figure I Effects of chlorthalidone on cardiovascular outcomes.

Note: Data from Roush et al; ${ }^{42}$ Dorsch et al; ${ }^{49}$ Roush et al; ${ }^{59}$ Dhalla et al. ${ }^{60}$

Abbreviations: Chlorthal, chlorthalidone; HCTZ, hydrochlorothiazide; CV, cardiovascular; HF, heart failure; SHEP, Systolic Hypertension in the Elderly Program; vs, versus; NS, not significant. 
heart disease outcome and any other cardiovascular disease outcome was similar for amlodipine, lisinopril, and chlorthalidone. However, chlorthalidone-based treatment had the lowest risk of heart failure, irrespective of sex. ${ }^{46}$ Furthermore, in a post hoc analysis of ALLHAT in hypertensive patients with a reduced glomerular filtration rate, the three drugs were similar in terms of reducing the risk of end-stage renal disease or achieving a $50 \%$ or greater decrement in glomerular filtration rate. ${ }^{47}$

Finally, it has been reported that the beneficial effects of chlorthalidone are not limited to its ability to reduce BP, and the pleiotropic effects of chlorthalidone may include improvements in oxidative status, endothelial function, and antiplatelet activity. ${ }^{48}$ Moreover, studies have shown that, compared with placebo, chlorthalidone has minor effects on fasting glucose and total cholesterol, ${ }^{48}$ and compared with HCTZ, significantly reduces total cholesterol and low-density lipoprotein cholesterol levels. ${ }^{49}$

\section{Hydrochlorothiazide versus chlorthalidone: what is the evidence?}

The relative antihypertensive potency and relative cardiovascular risk reduction have been investigated for HCTZ and chlorthalidone. ${ }^{50}$ In a randomized, single-blind, 8 -week active treatment crossover study, chlorthalidone $12.5 \mathrm{mg}$ /day (force-titrated to $25 \mathrm{mg} /$ day) and HCTZ $25 \mathrm{mg}$ /day (force-titrated to $50 \mathrm{mg} /$ day) were compared in untreated hypertensive patients. Compared with HCTZ $50 \mathrm{mg} /$ day, chlorthalidone $25 \mathrm{mg}$ /day reduced ambulatory systolic BP more effectively (mean 24-hour reduction $-7.4 \pm 1.7 \mathrm{mmHg}$ versus $-12.4 \pm 1.8 \mathrm{mmHg}$, respectively, $P=0.054$; mean nighttime reduction $-6.4 \pm 1.8 \mathrm{mmHg}$ versus $-13.5 \pm 1.9 \mathrm{mmHg}$, respectively, $P=0.009)$. However, these differences were not apparent when office BP measurements were considered (Table 1). ${ }^{51}$

In a randomized, double-blind, titrate-to-target BP trial, a fixed combination of azilsartan medoxomil and chlorthalidone was compared with a free combination of azilsartan medoxomil and HCTZ in 609 individuals with stage 2 primary hypertension and a mean baseline clinic BP of 164.6/95.4 mmHg. After 2 weeks of treatment with azilsartan medoxomil $40 \mathrm{mg}$ as monotherapy, $12.5 \mathrm{mg}$ of diuretic for 4 weeks (up to week 6) was added to treatment and then titrated to $25 \mathrm{mg}$ for another 4 weeks (up to week 10) if target BP was not achieved. At week 6, the combination containing chlorthalidone achieved a greater reduction in clinic systolic BP (-35.1 mmHg versus $-29.5 \mathrm{mmHg}$, respec- tively, mean difference $-5.6 \mathrm{mmHg} ; 95 \%$ confidence interval [CI] -8.3 to $-2.9 ; P<0.001)$, as well as a greater reduction in 24-hour ambulatory BP (mean difference $-5.8 \mathrm{mmHg}$; $95 \% \mathrm{CI}-8.4$ to $-3.2, P<0.001)$. As a result, more patients treated in the chlorthalidone group achieved their target $\mathrm{BP}$ at week $6(64.1 \%$ versus $45.9 \%, P<0.001)$, without a significant increase in drug discontinuations due to adverse events (Table 1). ${ }^{52}$

In a meta-analysis analyzing the dose-response relationship between HCTZ, chlorthalidone, and bendroflumethiazide with regard to $\mathrm{BP}$ and serum potassium and urate levels, 26 studies of HCTZ, three of chlorthalidone, and one of bendroflumethiazide were included, providing a total of 4,683 subjects in more than 53 comparison arms. Meta-regression of the effect of thiazides on systolic BP showed different antihypertensive effects, ie, bendroflumethiazide lowered BP more than chlorthalidone, and chlorthalidone lowered BP more than HCTZ. Similar findings were reported for diastolic BP (Table 1). ${ }^{53}$ The results of this study strongly suggest that $25 \mathrm{mg}$ of HCTZ should not be regarded as equivalent to $25 \mathrm{mg}$ of chlorthalidone. ${ }^{53}$

Another meta-analysis studying the effects of HCTZ and chlorthalidone on systolic BP and potassium levels included 108 clinical trials with HCTZ and 29 with chlorthalidone. Equivalence analysis suggested that the systolic BP reductions achieved with HCTZ and chlorthalidone were not equivalent within the low-dose range currently recommended. In fact, when evaluated on a milligram-permilligram basis, chlorthalidone generally produced slightly greater reductions in systolic BP. In contrast, within the same dosing range, the mean changes in potassium were similar (Table 1). ${ }^{54}$

In a retrospective study comparing the effects of switching from HCTZ to chlorthalidone in a population from the Veterans Affairs Ann Arbor Healthcare System, in which nearly three quarters of patients were taking three or more antihypertensive agents at the time of the medication change, there was a significant reduction in both systolic BP $(-15.8 \mathrm{mmHg}$; 95\% CI -8.9 to $-22.6 \mathrm{mmHg}, P<0.0001)$ and diastolic $\mathrm{BP}(-4.2 \mathrm{mmHg} ; 95 \% \mathrm{CI}-1.5$ to $-6.9 \mathrm{mmHg}$, $P=0.0035$, Table 1). ${ }^{55}$ A more recent study showed that, when combined with candesartan $8 \mathrm{mg}$, chlorthalidone $12.5 \mathrm{mg}$ was as effective as HCTZ $25 \mathrm{mg}$ in reducing central aortic pressure. However, whereas chlorthalidone significantly reduced pulse wave velocity, HCTZ only marginally reduced the augmentation index (Table 1). ${ }^{56}$

These beneficial effects of chlorthalidone over HCTZ with regard to BP levels translate into an improvement in 
Table I Summary of the most relevant studies comparing the efficacy of hydrochlorothiazide with chlorthalidone in patients with hypertension

\begin{tabular}{|c|c|c|}
\hline Study & Design & Comments \\
\hline Ernst et al ${ }^{51}$ & $\begin{array}{l}\text { Randomized, single-blind, 8-week, active treatment, } \\
\text { crossover study in which chlorthalidone } 12.5 \mathrm{mg} / \text { day } \\
\text { (force-titrated to } 25 \mathrm{mg} / \text { day) and HCTZ } 25 \mathrm{mg} / \text { day } \\
\text { (force-titrated to } 50 \mathrm{mg} / \text { day) were compared in } \\
\text { patients with untreated hypertension. } \\
\text { Thirty patients completed the first active treatment } \\
\text { period, whereas } 24 \text { patients completed both. }\end{array}$ & $\begin{array}{l}\text { Compared with HCTZ } 50 \mathrm{mg} / \text { day, chlorthalidone } \\
25 \mathrm{mg} / \text { day reduced ambulatory systolic BP more effectively } \\
(24 \text {-hour mean }-7.4 \pm 1.7 \mathrm{mmHg} \text { versus }-12.4 \pm 1.8 \mathrm{mmHg} \text {, } \\
\text { respectively, } P=0.054 ; \text { nighttime mean }-6.4 \pm 1.8 \mathrm{mmHg} \\
\text { versus }-13.5 \pm 1.9 \mathrm{mmHg} \text {, respectively, } P=0.009) \text {. } \\
\text { However, these differences were not apparent when office } \\
\text { BP measurements were considered (at study end, } \\
-10.8 \pm 3.5 \text { versus }-17.1 \pm 3.7 \text {, respectively, } P=0.84) \text {. }\end{array}$ \\
\hline Bakris et $\mathrm{al}^{52}$ & $\begin{array}{l}\text { Randomized, double-blind, titrate-to-target BP trial. } \\
\text { A fixed combination of azilsartan medoxomil and } \\
\text { chlorthalidone was compared with coadministration } \\
\text { of azilsartan medoxomil and HCTZ in } 609 \text { individuals } \\
\text { with stage } 2 \text { primary hypertension (mean baseline } \\
\text { clinic BP } 164.6 / 95.4 \mathrm{mmHg} \text { ). } \\
\text { After } 2 \text { weeks of treatment with azilsartan } \\
\text { medoxomil } 40 \mathrm{mg} \text { as monotherapy, } 12.5 \mathrm{mg} \text { of } \\
\text { diuretic for } 4 \text { weeks (up to week } 6 \text { ) was added to } \\
\text { treatment and then titrated to } 25 \mathrm{mg} \text { for another } \\
4 \text { weeks (up to week } 10 \text { ) if BP targets were not }\end{array}$ & $\begin{array}{l}\text { At week } 6 \text {, the combination containing chlorthalidone } \\
\text { achieved greater clinic systolic } B P \text { reductions }(-35 . I \mathrm{mmHg} \\
\text { versus }-29.5 \mathrm{mmHg} \text {, mean difference }-5.6 \mathrm{mmHg} ; P<0.00 \mathrm{I}) \text {, } \\
\text { as well as greater } 24 \text {-hour ambulatory } \mathrm{BP} \text { reduction (mean } \\
\text { difference }-5.8 \mathrm{mmHg} ; P<0.00 \mathrm{I}) \text {. } \\
\text { More patients in the chlorthalidone group achieved target } \\
\mathrm{BP} \text { at week } 6(64.1 \% \text { versus } 45.9 \%, P<0.00 \mathrm{I}) \text {. } \\
\text { Discontinuation due to adverse events was similar between } \\
\text { treated and control groups. }(9.3 \% \text { versus } 7.3 \% \text {, } \\
P=0.38) \text {. }\end{array}$ \\
\hline
\end{tabular}

$\begin{array}{ll}\text { Peterzan et al }\left.\right|^{53} & \text { Meta-analysis aiming to analyze the dose-response } \\ \text { relationships between HCTZ, chlorthalidone, and } \\ \text { bendroflumethiazide on BP, serum potassium, and } \\ \text { urate. } \\ \text { A total of } 26 \text { trials examining HCTZ, three } \\ \text { investigating chlorthalidone, and one investigating } \\ \text { bendroflumethiazide were included, with a total } \\ \text { of } 4,683 \text { subjects in more than } 53 \text { comparison arms. } \\ \text { Meta-analysis that studied the effects of HCTZ } \\ \text { and chlorthalidone on systolic BP and potassium. } \\ \text { A total of I08 clinical trials with HCTZ and } 29 \\ \text { with chlorthalidone were included from I948 to } \\ \text { July } 2008 .\end{array}$

Matthews et $\mathrm{a}^{55} \quad$ Retrospective study comparing the effects of changing from HCTZ to chlorthalidone in a veteran population $(n=40)$ from Veterans Affairs Ann Arbor Healthcare System, in which nearly three quarters of patients were taking three or more antihypertensive agents at the time of the medication change.

Kwon et a $\left.\right|^{56} \quad$ Open-label, randomized, prospective crossover study with an 8-week active treatment (candesartan $8 \mathrm{mg}$ with HCTZ $25 \mathrm{mg}$ or chlorthalidone $12.5 \mathrm{mg}$ ) and a 4-week washout period (only candesartan during this period). Twenty-eight treatment-naïve hypertensive patients were included.

Dorsch et $\mathrm{a}^{49} \quad$ Retrospective cohort analysis from the Multiple Risk Factor Intervention Trial (this trial was a primary prevention cardiovascular trial in which participants were men aged $35-57$ years and enrolled in 1973).
Metaregression of the effect of thiazides on systolic BP showed various antihypertensive effects, as follows: bendroflumethiazide $>$ chlorthalidone $>\mathrm{HCTZ}$ (the dose of each agent estimated to reduce systolic BP by $10 \mathrm{mmHg}$ was I.4, 8.6, and $26.4 \mathrm{mg}$, respectively).

Similar findings were found regarding diastolic BP.

Equivalence analysis suggested that the systolic BP reductions achieved with $\mathrm{HCTZ}$ and chlorthalidone were not equivalent within the low-dose range currently recommended.

When evaluated on a milligram-per-milligram basis, chlorthalidone generally produced slightly greater reductions in systolic BP.

By contrast, within the same dosing range, the mean changes in potassium were similar.

There was a significant reduction in both systolic BP $(-15.8 \mathrm{mmHg} ; P<0.000 \mathrm{I})$ and diastolic $\mathrm{BP}(-4.2 \mathrm{mmHg}$; $P=0.0035)$.

Combined with candesartan $8 \mathrm{mg}$, chlorthalidone $12.5 \mathrm{mg}$ was as effective as HCTZ $25 \mathrm{mg}$ in reducing central aortic pressure. However, whereas chlorthalidone significantly reduced pulse wave velocity, HCTZ only marginally reduced the augmentation index.

Although both drugs reduced cardiovascular events compared to those who took neither drug, chlorthalidone reduced cardiovascular events more effectively than HCTZ (by $49 \%$ and $35 \%$, respectively; $P<0.000$ I in both cases versus neither drug; $P=0.0016$ between both drugs). 
Table I (Continued)

\begin{tabular}{|c|c|c|}
\hline Study & Design & Comments \\
\hline Roush et $\mathrm{al}^{59}$ & $\begin{array}{l}\text { Systematic review of randomized trials in which } \\
\text { one arm was based on either HCTZ or } \\
\text { chlorthalidone, followed by two types of network } \\
\text { meta-analyses, ie, a drug-adjusted analysis and an } \\
\text { office systolic BP-adjusted analysis. } \\
\text { A total of three trials based on HCTZ and six } \\
\text { based on chlorthalidone were included. }\end{array}$ & $\begin{array}{l}\text { In the drug-adjusted analysis }(n=50,946) \text {, compared with } \\
\text { HCTZ, chlorthalidone reduced the risk of congestive } \\
\text { heart failure by } 23 \%(P=0.032) \text {; the risk for all } \\
\text { cardiovascular events was } 21 \%(P<0.000 \mathrm{I}) \text {. } \\
\text { In the office systolic BP-adjusted analysis ( } \mathrm{n}=78,350) \text {, } \\
\text { compared with HCTZ, chlorthalidone reduced the risk } \\
\text { of cardiovascular events by } 18 \%(P=0.024) \text {. }\end{array}$ \\
\hline Dhalla et $a^{60}$ & $\begin{array}{l}\text { Propensity score-matched observational cohort study with } \\
\text { up to } 5 \text { years of follow-up performed in patients } \geq 66 \text { years who } \\
\text { were newly treated with chlorthalidone or HCTZ and had } \\
\text { not been hospitalized for heart failure, stroke, or } \\
\text { myocardial infarction in the previous year }(n=29,873) \text {. }\end{array}$ & $\begin{array}{l}\text { Chlorthalidone was not associated with fewer adverse } \\
\text { cardiovascular events or deaths compared with HCTZ } \\
\text { (adjusted HR } 0.93 ; 95 \% \mathrm{Cl} 0.81-1.06 \text { ). }\end{array}$ \\
\hline
\end{tabular}

Abbreviations: $\mathrm{HCTZ}$, hydrochlorothiazide; $\mathrm{BP}$, blood pressure; $\mathrm{Cl}$, confidence interval; $\mathrm{HR}$, hazards ratio.

terms of subclinical organ damage. Data from the Multiple Risk Factor Intervention Trial showed that, at the individual level, the Sokolow-Lyon index and left ventricular mass were significantly lower in men receiving chlorthalidone than in those receiving HCTZ at 48 months and 84 months of follow-up. ${ }^{57}$ It has also been observed that chlorthalidone is significantly more effective than bendroflumethiazide (a thiazide diuretic) in reducing epinephrine-mediated platelet aggregation. Moreover, although both diuretics reduced vascular permeability to albumin, only chlorthalidone increased angiogenesis. ${ }^{58}$

More importantly, other studies have investigated whether these beneficial properties of chlorthalidone when compared with HCTZ result in better cardiovascular outcomes. A retrospective cohort analysis from the Multiple Risk Factor Intervention Trial showed that, in hypertensive patients at high risk of cardiovascular events, although both drugs reduced cardiovascular events compared with those who took neither drug, chlorthalidone reduced cardiovascular events more effectively than HCTZ (Table 1 and Figure 1). ${ }^{49}$

A systematic review of randomized trials in which one arm was based on either HCTZ or chlorthalidone, followed by two types of network meta-analyses, ie, a drug-adjusted analysis and an office systolic BP-adjusted analysis, included three trials based on HCTZ and six based on chlorthalidone. In the drug-adjusted analysis $(\mathrm{n}=50,946)$, compared with HCTZ, chlorthalidone reduced the risk of congestive heart failure by $23 \%$ ( $95 \%$ CI 2-39, $P=0.032$ ), and the risk for all cardiovascular events was $21 \%(95 \% \mathrm{CI} 12-28, P<0.0001)$. In the office systolic BP-adjusted analysis $(n=78,350)$, compared with HCTZ, chlorthalidone reduced the risk of cardiovascular events by $18 \%(95 \%$ CI $3-30, P=0.024$, Table 1 and Figure 1). ${ }^{59}$ However, other studies showed that, in older adults, chlorthalidone as typically prescribed was not associated with fewer adverse cardiovascular events or deaths compared with HCTZ (Table 1 and Figure 1) ${ }^{60}$

As a result, the question concerning whether chlorthalidone is better than HCTZ at reducing cardiovascular events in hypertensive patients remains unresolved. Head-to-head trials have shown that chlorthalidone is more effective than HCTZ in reducing BP levels, particularly during the nighttime due to the longer duration of action of chlorthalidone, and in decreasing left ventricular hypertrophy. Moreover, although no head-to-head outcomes trials comparing the efficacy of chlorthalidone and HCTZ are available, and data regarding this issue is provided from post hoc analyses, the majority of the studies have shown superiority for chlorthalidone in reducing cardiovascular events, probably not only due to the higher antihypertensive efficacy of chlorthalidone but also as a result of its pleiotropic effects. ${ }^{61}$

Despite the guidelines, such as those of the National Institute for Health and Clinical Excellence, recommending that when a diuretic is prescribed, a thiazide-like diuretic, such as chlorthalidone or indapamide, should be preferred over bendroflumethiazide or HCTZ, ${ }^{62}$ the fact is that prescriptions for HCTZ outnumber those for chlorthalidone by more than 20 -fold. ${ }^{59}$

\section{Efficacy and safety of indapamide}

Several studies have analyzed the efficacy and safety of indapamide as add-on therapy, particularly with perindopril and delapril. A 9-month study comparing the efficacy and tolerability of three different strategies for the treatment of hypertension, ie, a low-dose combination (perindopril $2 \mathrm{mg}$ and indapamide $0.625 \mathrm{mg}$ with the possibility to increase to 4 and $1.25 \mathrm{mg}$, respectively), sequential monotherapy (treatment initiated with atenolol $50 \mathrm{mg}$, replaced if necessary by losartan $50 \mathrm{mg}$, and then by amlodipine $5 \mathrm{mg}$ ), 
and stepped-care (valsartan $40 \mathrm{mg}$, then $80 \mathrm{mg}$, and finally if required the addition of HCTZ $12.5 \mathrm{mg}$ ), included 533 patients with uncomplicated essential hypertension. At the end of the study, $62 \%$ of patients in the low-dose combination group achieved their target BP, compared with $49 \%$ in the sequential monotherapy group $(P=0.02)$ and $47 \%$ in the stepped-care group $(P=0.005)$. This better BP control was not associated with an increase in side effects. ${ }^{63}$

In a 3-month, open-label, observational study, outpatients with hypertension who did not attain their target BP with antihypertensive treatment were included if their treating physician switched them to fixed-dose perindopril $10 \mathrm{mg}$ /indapamide $2.5 \mathrm{mg}$ according to the clinical criteria of the physicians. Nearly 9,300 patients were enrolled. At the end of the study, $72.7 \%$ of patients had achieved their BP goal. Reductions in total cholesterol, low-density lipoprotein cholesterol, triglycerides, fasting glucose, and uric acid levels were clinically significant, without changes in sodium or potassium levels. These changes in the metabolic profile were likely due to withdrawal of previous treatment with thiazides and beta-blockers. ${ }^{64}$

In a 6-month, prospective, open-label clinical study performed in 397 patients with hypertension and type 2 diabetes, a fixed-dose combination of perindopril/indapamide (from $5 / 1.25 \mathrm{mg}$ to $10 / 2.5 \mathrm{mg}$ if BP targets were not attained) was prescribed (started, switched, or added to previous therapy). At the end of the study, $84 \%$ of patients taking perindopril/indapamide $5 / 1.25 \mathrm{mg}$ alone and $90 \%$ of patients taking perindopril/indapamide $10 / 2.5 \mathrm{mg}$ alone showed normalization of their BP levels, with good tolerability. Microalbuminuria decreased in $75 \%$ of patients with microalbuminuria. ${ }^{65}$

In an other study performed in more than 2,300 hypertensive patients being seen in daily clinical practice, $69 \%$ of whom had been unsuccessfully treated with other antihypertensive agents, $4.6 \%$ of whom had not tolerated previous treatments, and $26.8 \%$ of whom were newly diagnosed with hypertension, $87.1 \%$ achieved their target BP after 3 months of treatment with perindopril/indapamide $(2.5 / 0.625 \mathrm{mg}$ or $5 / 1.25 \mathrm{mg}$ uptitrated to $10 / 2.5 \mathrm{mg}$ at any time during the study if required). BP reductions were similar, irrespective of the presence of diabetes mellitus, metabolic syndrome, or left ventricular hypertrophy. Moreover, no significant changes in laboratory parameters were observed and patient quality of life was improved. ${ }^{66}$

In a systematic review of the efficacy and safety of a perindopril/indapamide $2 \mathrm{mg} / 0.625 \mathrm{mg}$ combination as first-line treatment for hypertension, a total of 11 trials with
5,936 individuals (five studies versus placebo and six studies versus routine antihypertensive agents) were included. Compared with placebo, the combination of perindopril/ indapamide effectively reduced BP levels (systolic BP $-9.03 \mathrm{mmHg}, P<0.01$; diastolic BP $-5.09 \mathrm{mmHg}$, $P<0.01)$. Similarly, compared with routine antihypertensive agents, the combination of perindopril/indapamide was more effective in reducing BP (systolic $\mathrm{BP}-3.72 \mathrm{mmHg}, P=0.03$; diastolic BP $-1.71 \mathrm{mmHg}, P<0.01$ ). Adverse events and withdrawal rates were similar between the perindoprilindapamide group and the placebo or routine antihypertensive drug groups. ${ }^{67}$

Regarding organ damage, the ADVANCE (Action in Diabetes and Vascular Disease) Echocardiography Substudy showed that although the perindopril-indapamide combination did not improve left ventricular diastolic function in patients with diabetes to a greater extent than placebo, this combination significantly reduced BP and left ventricular mass. $^{68}$

Moreover, it was reported that approximately $85 \%$ of physicians considered the efficacy and tolerability of perindopril/ indapamide $2 / 0.625 \mathrm{mg}$ in hypertensive patients with diabetes seen in daily clinical practice to be "good" or "very good" and that $93 \%$ of patients were "satisfied" or "very satisfied" with this therapy. ${ }^{69}$

On the other hand, it has been shown that the combination of perindopril and indapamide has additional beneficial effects. Improvements in vascular function have been demonstrated in hypertensive patients by a reduction in wave reflection, lowering of peripheral arterial stiffness, and improvement in endothelial function, ${ }^{70}$ and reductions in BP and left ventricular mass index in hypertensive patients with left ventricular hypertrophy, along with improvements in resting and hyperemic myocardial blood flow. ${ }^{71}$ Experimental data in rats have shown that the improvements in coronary flow observed with this combination are due to reverse remodeling of intramural coronary arterioles and improved microvascular function. ${ }^{71}$ Moreover, it has been reported that indapamide decreases BP, left ventricular hypertrophy, and the collagen ratio. ${ }^{72}$

Perhaps more importantly, clinical trials have investigated the benefits of the combination of perindopril and indapamide with regard to cardiovascular outcomes. PROGRESS (Perindopril pROtection aGainst REcurrent Stroke Study) was performed to assess the effects of perindopril $(4 \mathrm{mg}$ daily), with the addition of indapamide at the discretion of treating physicians, in patients with a history of stroke or transient ischemic attack, irrespective of the presence of 
hypertension. A total of 6,105 individuals were randomized to active treatment or placebo. After 4 years of follow-up, active treatment was associated with a $28 \%$ reduction in the risk of stroke $(43 \%$ in those treated with the combined therapy), and a $26 \%$ reduction in the risk of total major vascular events (Figure 2). ${ }^{73}$

In ADVANCE, the effects of a combination of perindopril and indapamide on serious vascular events were investigated in 11,140 patients with type 2 diabetes, irrespective of their initial BP levels or use of antihypertensive drugs. Patients were randomized to active treatment or placebo in addition to current therapy. After a mean follow-up of 4.3 years, the perindopril/indapamide combination was associated with a $9 \%$ reduction in the risk of major macrovascular or microvascular events (hazards ratio [HR] 0.91; 95\% CI 0.83-1.00, $P=0.04$ ), an $18 \%$ reduction in the risk of death from cardiovascular disease (HR 0.82; 95\% CI 0.68-0.98, $P=0.03$ ), and a $14 \%$ reduction in risk of death from any cause (HR 0.86; 95\% CI 0.75-0.98, $P=0.03$, Figure 2). ${ }^{74}$ A substudy of ADVANCE showed that active treatment with a combination of perindopril and indapamide reduced BP levels safely and reduced the risk of major clinical outcomes in patients with type 2 diabetes and aged over 75 years. ${ }^{75}$ Similarly, the beneficial effects of the perindopril/indapamide combination on cardiovascular and renal outcomes and death were consistent across all stages of chronic kidney disease at baseline. ${ }^{76}$

In HYVET (the Hypertension in the Very Elderly Trial), 3,845 patients (aged $\geq 80$ years) with hypertension and a sustained systolic BP $\geq 160 \mathrm{mmHg}$ were randomized to indapamide (sustained-release, $1.5 \mathrm{mg}$ ) or placebo. Perindopril ( 2 or $4 \mathrm{mg}$ ) or placebo was added when required to achieve a BP goal $<150 / 80 \mathrm{mmHg}$. After a mean follow-up of 1.8 years,

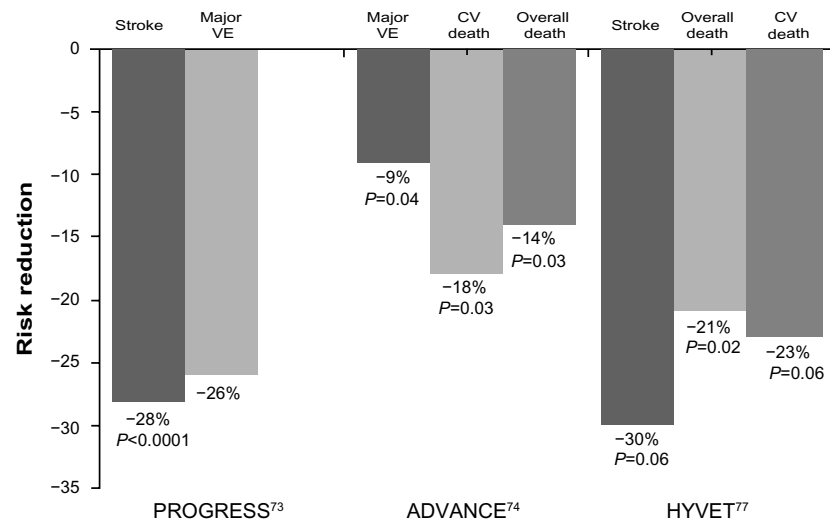

Figure 2 Effects of perindopril and indapamide combination on cardiovascular outcomes.

Note: Data from PROGRESS Collaborative Group; ${ }^{73}$ Patel A et al $;{ }^{74}$ and Beckett NS et al. ${ }^{77}$

Abbreviations: CV, cardiovascular; VE, vascular events; PROGRESS, Perindopril pROtection aGainst REcurrent Stroke Study; ADVANCE, Action in Diabetes and Vascular Disease study; HYVET, the Hypertension in the Very Elderly Trial. active treatment was associated with a $30 \%$ reduction in the risk of fatal or nonfatal stroke $(P=0.06)$, a $39 \%$ reduction in the risk of death from stroke $(P=0.05)$, a $21 \%$ reduction in the risk of death from any cause $(P=0.02)$, a $23 \%$ reduction in the risk of death from cardiovascular causes $(P=0.06)$, and a $64 \%$ reduction in the risk of heart failure $(P<0.001$, Figure 2). ${ }^{77}$

In the 1-year, open-label active treatment extension of HYVET, patients on active treatment continued taking the active drug, and those initially assigned to placebo received active BP-lowering treatment. Those patients initially assigned to active treatment had less total mortality (HR 0.48; 95\% CI 0.26-0.87, $P=0.02$ ) and cardiovascular mortality (HR $0.19 ; 95 \%$ CI $0.04-0.87, P=0.03) .^{78}$

On the other hand, other studies have analyzed the antihypertensive efficacy of a combination of indapamide and delapril in hypertensive patients. ${ }^{79-82}$ In DIMS II (Delapril-Indapamide Multicenter Study II), approximately 800 patients with uncomplicated mild to moderate hypertension were randomized to receive delapril/indapamide or captopril/HCTZ for 6 months. At the end of the study, more patients treated with delapril/ indapamide responded to treatment $(92.6 \%$ versus $85.2 \%$, $P<0.001)$. Side effects occurred in $7.6 \%$ and $8.1 \%$ of patients, respectively. ${ }^{80}$ Moreover, in elderly patients aged 65-85 years with a sitting BP of 160-200/95-115 $\mathrm{mmHg}$, the combination of delapril $30 \mathrm{mg}$ plus indapamide $1.25 \mathrm{mg}$ once daily effectively reduced BP levels as well as left ventricular mass index. ${ }^{81}$ Similarly, treatment with this combination was associated with a significant increase in glomerular filtration rate. ${ }^{82}$

\section{Hydrochlorothiazide versus indapamide: what is the evidence?}

As with chlorthalidone, several studies have determined the relative antihypertensive efficacy and relative cardiovascular risk reduction for HCTZ and indapamide. It has been observed in hypertensive patients aged $65-80$ years that, indapamide sustained-release was an effective and well tolerated antihypertensive therapy over a 12 -month period, even after a switch from amlodipine or HCTZ (Table 2) ${ }^{83} \mathrm{In}$ a small randomized clinical trial of patients with I-II degree high and very high risk hypertension, after 6 months of treatment, the fixed combination of perindopril/indapamide 4/1.25 mg was superior to a combination of captopril/HCTZ $50 / 25 \mathrm{mg}$ (Table 2). ${ }^{84}$

In a Russian study, administration of perindopril arginine/ indapamide $(10 \mathrm{mg} / 2.5 \mathrm{mg})$ instead of ACEi or ARB plus 
Table 2 Summary of most relevant studies comparing the efficacy of hydrochlorothiazide with indapamide in patients with hypertension

\begin{tabular}{|c|c|c|}
\hline Study & Design & Comments \\
\hline Leonetti et $\mathrm{a}^{83}$ & $\begin{array}{l}\text { Open, I2-month, follow-up study of } 444 \text { patients treated } \\
\text { with indapamide SR, who were responders and/or achieved } \\
\text { target BP levels following a 3-month, randomized, } \\
\text { controlled, double-blind, short-term comparison of } \\
\text { indapamide SR versus HCTZ } 25 \mathrm{mg} \text { and amlodipine } 5 \mathrm{mg} \text {. }\end{array}$ & $\begin{array}{l}\text { After } 12 \text { months of follow-up, treatment } \\
\text { with indapamide SR was associated with a } \\
\text { reduction of BP (-24.0/-13.I mmHg); } 80.1 \% \\
\text { of patients achieved their BP goals. }\end{array}$ \\
\hline Nedogoda et a ${ }^{84}$ & $\begin{array}{l}\text { Clinical trial in which } 40 \text { patients with I-II degree high } \\
\text { and very high risk hypertension were randomized to } \\
\text { receive fixed-dose combinations of perindopril/indapamide } \\
4 / 1.25 \mathrm{mg} \text { or captopril/HCTZ 50/25 mg. }\end{array}$ & $\begin{array}{l}\text { After } 6 \text { months of treatment, the fixed } \\
\text { combination of perindopril/indapamide } \\
4 / 1.25 \mathrm{mg} \text { was superior to the combination } \\
\text { of captopril/HCTZ } 50 / 25 \mathrm{mg} \text {. }\end{array}$ \\
\hline Karpov 85 & $\begin{array}{l}\text { In this study, perindopril arginine/indapamide ( } 10 \mathrm{mg} / 2.5 \mathrm{mg}) \\
\text { was administered instead of an ACEi or ARB plus HCTZ } \\
\text { in more than } 2,100 \text { patients with inadequately controlled } \\
\text { hypertension. }\end{array}$ & $\begin{array}{l}\text { Treatment with the perindopril arginine/ } \\
\text { indapamide combination significantly reduced BP } \\
\text { levels from } 177 / 99 \mathrm{mmHg} \text { to } 149 / 89 \mathrm{mmHg} \\
\text { after } 2 \text { weeks of treatment and to } 130 / 80 \mathrm{mmHg} \\
\text { after } 3 \text { months of treatment, with good } \\
\text { tolerance of medication. }\end{array}$ \\
\hline Cremonesi et $\mathrm{a}^{86}$ & $\begin{array}{l}\text { In this } 12 \text {-week randomized study, fixed combinations } \\
\text { of delapril/indapamide } 30 / 2.5 \mathrm{mg} \text { and fosinopril/HCTZ } \\
20 / / 2.5 \mathrm{mg} \text { were compared in I7I patients with mild to } \\
\text { moderate hypertension. } \\
\text { Normalization of BP was defined as sitting diastolic BP } \\
\leq 90 \mathrm{mmHg} \text { and responders as those having a sitting diastolic } \\
\text { BP reduction of } 10 \mathrm{mmHg} \text { or diastolic BP } \leq 90 \mathrm{mmHg} \text {. }\end{array}$ & $\begin{array}{l}\text { The proportion of patients with normalized } \\
\text { BP was similar between the two groups ( } 87.4 \% \\
\text { versus } 81 \%) \text { and for those who responded to } \\
\text { therapy }(92 \% \text { versus } 86.9 \% \text {, respectively). } \\
\text { Both combinations were well tolerated. }\end{array}$ \\
\hline Circelli et al ${ }^{87}$ & $\begin{array}{l}\text { Meta-analysis comparing the efficacy and safety of a combination } \\
\text { of delapril and indapamide with that of different ACEi plus } \\
H C T Z \text { combinations in patients with mild to moderate } \\
\text { hypertension. } \\
\text { Four head-to-head randomized controlled trials ( } n=643 \\
\text { and } n=629 \text {, respectively) were included. }\end{array}$ & $\begin{array}{l}\text { The proportions of patients with normalized } \\
\mathrm{BP} \text { values (OR I.32; } 95 \% \mathrm{CI} \text { I.04-I.68; } P=0.024) \\
\text { and who were responders (OR I.58; } 95 \% \\
\mathrm{CI} \text { I.22-2.04; } P=0.002 \text { ) were higher with the } \\
\text { delapril/indapamide combination. } \\
\text { The proportion of patients who withdrew from } \\
\text { treatment due to side effects was lower with the } \\
\text { delapril/indapamide combination ( } 2.3 \% \text { versus } \\
4.8 \% ; P=0.018 \text { ). }\end{array}$ \\
\hline
\end{tabular}

Abbreviations: $\mathrm{HCTZ}$, hydrochlorothiazide; $\mathrm{BP}$, blood pressure; $\mathrm{Cl}$, confidence interval; OR, odds ratio; $\mathrm{ACEi}$, angiotensin-converting enzyme inhibitor; $\mathrm{ARB}$, angiotensin receptor blocker; SR, sustained release.

HCTZ in more than 2,100 patients with inadequately controlled hypertension significantly reduced BP levels from $177 / 99 \mathrm{mmHg}$ to $149 / 89 \mathrm{mmHg}$ after 2 weeks of treatment, and to $130 / 80 \mathrm{mmHg}$ after 3 months of treatment, with good tolerance of medication (Table 2). ${ }^{85}$

In a randomized 12-week study, fixed combinations of delapril $(30 \mathrm{mg}$ ) plus indapamide $(2.5 \mathrm{mg})$ and fosinopril (20 mg) plus HCTZ (12.5 mg) were compared in 171 patients with mild to moderate hypertension; the proportion of patients who achieved normal BP, defined as a sitting diastolic BP $\leq 90 \mathrm{mmHg}$, was similar between the groups ( $87.4 \%$ versus $81 \%$, respectively) and also with regard to those who responded to therapy, defined as a sitting diastolic BP reduction of $10 \mathrm{mmHg}$ or diastolic $\mathrm{BP} \leq 90 \mathrm{mmHg}$ ( $92 \%$ versus $86.9 \%$, respectively). Both combinations were well tolerated (Table 2). ${ }^{86}$

A meta-analysis comparing the efficacy and safety of a combination of delapril and indapamide with different
ACEi/HCTZ combinations in patients with mild to moderate hypertension included four head-to-head randomized controlled trials ( $\mathrm{n}=643$ and 629 , respectively). The proportion of patients who achieved normal BP values or were responders was higher with the delapril/indapamide combination ( $P=0.024$ and $P=0.002$, respectively). Moreover, the number of withdrawals due to drug-related side effects was lower with the delapril/indapamide combination $(2.3 \%$ versus $4.8 \%$, respectively, $P=0.018$, Table 2). ${ }^{87}$

Not only the antihypertensive efficacy of indapamide and HCTZ has been compared. In a small study that specifically compared the metabolic and endothelial effects of indapamide retard with those of HCTZ, patients with hypertension received either indapamide retard $(1.5 \mathrm{mg} /$ day $)$ or HCTZ ( $25 \mathrm{mg} /$ day) for 12 weeks. At the end of the study, both drugs reduced BP levels to a similar extent. However, whereas indapamide retard was metabolically neutral, the patients who received HCTZ showed a significant increase in 
triglycerides $(+15.3 \%, P<0.05)$ and glucose levels $(+12.2 \%$, $P<0.05)$. Moreover, there was a tendency for endotheliumdependent vasodilation to improve with indapamide and become worse with HCTZ. ${ }^{8}$ Finally, in an experimental study performed in rats, treatment with losartan was associated with antiatherogenic activity, reflected by lipid-lowering and an antioxidant effect in erythrocytes. However, whereas this activity was abolished by addition of HCTZ to losartan, it remained unchanged when indapamide was added. Moreover, in contrast with indapamide, treatment with $\mathrm{HCTZ}$ was associated with hypokalemia. ${ }^{89}$

\section{Conclusion and place in therapy}

When considering antihypertensive drugs as monotherapy, although the JNC 7 (Seventh Report of the Joint National Committee on Prevention, Detection, Evaluation, and Treatment of High Blood Pressure) $)^{90}$ indicated that five classes should be considered as initial therapy and recommended thiazide-type diuretics as initial therapy for most patients, the JNC 8 recommends selection between four specific medication classes (ACEi, ARB, calcium channel blockers, and diuretics). ${ }^{16}$ Moreover, the 2013 European guidelines reconfirm that all major classes of antihypertensive agents (diuretics, beta-blockers, calcium channel blockers, ACEi, and ARB) are suitable for the initiation and maintenance of antihypertensive therapy. ${ }^{17}$ As a result, it is very likely that diuretics will no longer be recommended as the only first option in monotherapy. Of note, when a diuretic is used for the treatment of hypertension, thiazide and thiazide-like diuretics are mainly prescribed. Loop diuretics are not recommended for the treatment of hypertension, except in the event of advanced renal impairment, and are commonly prescribed when heart failure is also present.

The addition of diuretics to an ACEi or ARB for reducing $\mathrm{BP}$ to recommended targets is an adequate choice in patients with hypertension. Thiazides, mainly HCTZ and thiazide-type diuretics, such as chlorthalidone and indapamide, have been widely used for this purpose. However, not all diuretics seem to be equal, as evident in this review. Thus, given that the plasma elimination half-lives of chlorthalidone and indapamide are longer than that of HCTZ, better antihypertensive efficacy over 24 hours may be assured using these agents. In fact, the majority of studies have shown greater $\mathrm{BP}$ reductions with chlorthalidone or indapamide than with HCTZ. ${ }^{50,91}$

Moreover, chlorthalidone and indapamide have shown some clinically relevant additional benefits. Chlorthalidone can reduce platelet aggregation and vascular permeability, stimulate angiogenesis, and improve oxidative status, endothelial function, and antiplatelet activity. ${ }^{41,92}$ Moreover, compared with placebo, chlorthalidone has only small effects on fasting glucose and total cholesterol, ${ }^{48}$ and compared with HCTZ, chlorthalidone is associated with significantly lower total cholesterol and low-density lipoprotein cholesterol levels. ${ }^{49}$ Similarly, indapamide has demonstrated no negative impact on glucose or lipid metabolism. ${ }^{93}$

However, more importantly, although addition of HCTZ to renin angiotensin system inhibitors has been shown to effectively reduce BP levels, and decreasing BP to recommended targets improves the cardiovascular prognosis, a reduction in outcomes using low doses of HCTZ as add-on therapy has not yet been demonstrated. ${ }^{20}$ In contrast, although head-to-head clinical outcomes trials comparing the effects of indapamide or chlorthalidone with HCTZ are not available, indirect comparisons and post hoc analyses suggest that the use of chlorthalidone or indapamide is associated with a reduction in cardiovascular events. ${ }^{42,73,74,77}$ On the other hand, the benefits of indapamide with regard to cardiovascular outcomes have been shown only when indapamide is combined with perindopril, but not with other antihypertensive drugs.

Finally, hypokalemia is a potential side effect of thiazide and thiazide-like diuretics that may decrease the beneficial effects of these drugs in patients with hypertension. However, the risk of hypokalemia at the doses usually prescribed for this purpose is low. Moreover, combination with renin angiotensin system inhibitors may reduce this potential limitation. ${ }^{18-21}$ Despite that, addition of potassium supplements or potassium-sparing diuretics, including aldosterone receptor blockers (such as spironolactone and eplerenone) or epithelial sodium channel blockers (such as amiloride and triamterene) can sometimes be necessary, depending on the clinical characteristics of the patient. ${ }^{94}$ Combination with an aldosterone receptor blocker may be particularly beneficial in hypertensive patients with heart failure. ${ }^{95-97}$

Despite these limitations, the evidence suggests that the use of a thiazide-like diuretic, such as chlorthalidone or indapamide, appears to be a preferable option over HCTZ when combined therapy with a renin angiotensin system inhibitor is required. However, the diuretic used most often as add-on therapy in clinical practice is HCTZ. ${ }^{98}$

\section{Disclosure}

The authors have no conflicts of interests directly related to this work. 


\section{References}

1. Barrios V, Escobar C. Is a new crash coming? J Hypertens Open Access. 2012;1:e105.

2. Lawes CM, Vander Hoorn S, Rodgers A; International Society of Hypertension. Global burden of blood-pressure-related disease, 2001. Lancet. 2008;371(9623):1513-1518.

3. Pereira M, Lunet N, Azevedo A, Barros H. Differences in prevalence, awareness, treatment and control of hypertension between developing and developed countries. J Hypertens. 2009;27(5):963-975.

4. Stephens MM, Fox BA, Maxwell L. Therapeutic options for the treatment of hypertension in children and adolescents. Clin Med Insights Circ Respir Pulm Med. 2012;6:13-25.

5. Wijeysundera HC, Machado M, Farahati F, et al. Association of temporal trends in risk factors and treatment uptake with coronary heart disease mortality, 1994-2005. JAMA. 2010;303(18):1841-1847.

6. Flores-Mateo G, Grau M, O’Flaherty M, et al. Analyzing the coronary heart disease mortality decline in a Mediterranean population: Spain 1988-2005. Rev Esp Cardiol. 2011;64(11):988-996.

7. Mancia G, Messerli F, Bakris G, et al. Blood pressure control and improved cardiovascular outcomes in the International Verapamil SR-Trandolapril Study. Hypertension. 2007;50(2):299-305.

8. Egan BM, Zhao Y, Axon RN. US Trends in prevalence, awareness, treatment, and control of hypertension, 1988-2008. JAMA. 2010;303(20):2043-2050.

9. McAlister FA, Wilkins K, Joffres M, et al. Changes in the rates of awareness, treatment and control of hypertension in Canada over the past two decades. CMAJ. 2011;183(9):1007-1013.

10. Fasce E, Campos I, Ibáñez P, et al. Trends in prevalence, awareness, treatment and control of hypertension in urban communities in Chile. J Hypertens. 2007;25(9):1807-1811.

11. Cífková R, Skodová Z, Bruthans J, et al. Longitudinal trends in cardiovascular mortality and blood pressure levels, prevalence, awareness, treatment, and control of hypertension in the Czech population from 1985 to 2007/2008. J Hypertens. 2010;28(11):2196-2203.

12. Llisterri JL, Rodriguez-Roca GC, Escobar C, et al; on behalf of the Working Group of Arterial Hypertension of the Spanish Society of Primary Care Physicians (Group HTASEMERGEN); and the PRESCAP 2010 investigators. Treatment and blood pressure control in Spain during 2002-2010. J Hypertens. 2012;30(12):2425-2431.

13. Barrios V, Escobar C. Letter from Barrios and Escobar regarding article, "trends in antihypertensive medication use and blood pressure control among United States adults with hypertension: the National Health and Nutrition Examination Survey, 2001 to 2010". Circulation. 2013;127(24):e859.

14. Escobar C, Echarri R, Barrios V. Emerging drug combinations to optimize renovascular protection and blood pressure goals. Int J Nephrol Renovasc Dis. 2012;5:69-80.

15. Escobar C, Barrios V. Combined therapy in the treatment of hypertension. Fundam Clin Pharmacol. 2010;24(1):3-8.

16. James PA, Oparil S, Carter BL, et al. 2014 Evidence-Based Guideline for the Management of High Blood Pressure in Adults: Report From the Panel Members Appointed to the Eighth Joint National Committee (JNC 8). JAMA. 2014;311(5):507-520.

17. Mancia G, Fagard R, Narkiewicz K, et al. 2013 ESH/ESC guidelines for the management of arterial hypertension: the Task Force for the Management of Arterial Hypertension of the European Society of Hypertension (ESH) and of the European Society of Cardiology (ESC). Eur Heart J. 2013;34(28):2159-2219.

18. Motwani JG. Combining renin-angiotensin-aldosterone system blockade with diuretic therapy for treatment of hypertension. J Renin Angiotensin Aldosterone Syst. 2002;3(2):72-78.

19. Barrios V, Escobar C. Olmesartan medoxomil plus hydrochlorothiazide for treating hypertension. Expert Opin Pharmacother. 2008;9(1):129-136.

20. Barrios V, Escobar C. Azilsartan medoxomil in the treatment of hypertension: the definitive angiotensin receptor blocker? Expert Opin Pharmacother. 2013;14(16):2249-2261.
21. Barrios V, Escobar C. Complementary mechanisms of action and rationale for the fixed combination of perindopril and indapamide in treating hypertension - update on clinical utility. Integr Blood Press Control. 2010;3:11-19.

22. Carter BL, Ernst ME, Cohen JD. Hydrochlorothiazide versus chlorthalidone: evidence supporting their interchangeability. Hypertension. 2004;43(1):4-9.

23. Giudicelli JF, Richer C, Mattei A. Pharmacokinetics and biological effects of captopril and hydrochlorothiazide after acute and chronic administration either alone or in combination in hypertensive patients. Br J Clin Pharmacol. 1987;23 Suppl 1:51S-63S.

24. Weir SJ, Dimmitt DC, Lanman RC, Morrill MB, Geising DH. Steady-state pharmacokinetics of diltiazem and hydrochlorothiazide administered alone and in combination. Biopharm Drug Dispos. 1998;19(6):365-371.

25. Allen JH, McKenney JM, Stratton MA, Link K. Antihypertensive effect of hydrochlorothiazide administered once or twice daily. Clin Pharm. 1982;1(3):239-243.

26. Kohvakka A, Salo H, Gordin A, Eisalo A. Antihypertensive and biochemical effects of different doses of hydrochlorothiazide alone or in combination with triamterene. Acta Med Scand. 1986;219(4): 381-386.

27. Cushman WC, Khatri I, Materson BJ, et al. Treatment of hypertension in the elderly, III: response of isolated systolic hypertension to various doses of hydrochlorothiazide: results of a Department of Veterans Affairs cooperative study. Department of Veterans Affairs Cooperative Study Group on Antihypertensive Agents. Arch Intern Med. 1991;151(10):1954-1960.

28. Jounela AJ, Lilja M, Lumme J, et al. Relation between low dose of hydrochlorothiazide, antihypertensive effect and adverse effects. Blood Press. 1994;3(4):231-235.

29. Materson BJ, Oster JR, Michael UF, et al. Dose response to chlorthalidone in patients with mild hypertension: efficacy of a lower dose. Clin Pharmacol Ther. 1978;24(2):192-198.

30. Morledge JH, Ettinger B, Aranda J, et al. Isolated systolic hypertension in the elderly: a placebo controlled, dose-response evaluation of chlorthalidone. J Am Geriatr Soc. 1986;34(3):199-206.

31. Schiavi P, Jochemsen R, Guez D. Pharmacokinetics of sustained and immediate release formulations of indapamide after single and repeated oral administration in healthy volunteers. Fundam Clin Pharmacol. 2000;14(2):139-146.

32. Robinson DM, Wellington K. Indapamide sustained release: a review of its use in the treatment of hypertension. Drugs. 2006;66(2):257-271.

33. Guerrero P, Fuchs FD, Moreira LM, et al. Blood pressure-lowering efficacy of amiloride versus enalapril as add-on drugs in patients with uncontrolled blood pressure receiving hydrochlorothiazide. Clin Exp Hypertens. 2008;30(7):553-564.

34. Neutel JM, Saunders E, Bakris GL, et al. The efficacy and safety of low- and high-dose fixed combinations of irbesartan/ hydrochlorothiazide in patients with uncontrolled systolic blood pressure on monotherapy: the INCLUSIVE trial. $J$ Clin Hypertens (Greenwich). 2005;7(10):578-586.

35. Karlson BW, Zetterstrand S, Olofsson B, Elmfeldt D. A dose-response analysis of candesartan-hydrochlorothiazide combination therapy in patients with hypertension. Blood Press. 2009;18(3):149-156.

36. Edes I, Burgess L, Parow W, et al. Combination therapy with candesartan cilexetil $32 \mathrm{mg}$ and hydrochlorothiazide $25 \mathrm{mg}$ provides the full additive antihypertensive effect of the components: a randomized, double-blind, parallel-group study in primary care. Clin Drug Investig 2009;29(5):293-304.

37. Bönner G, Calder B, Dzyak G, et al. Antihypertensive efficacy and tolerability of candesartan-hydrochlorothiazide $32 / 12.5 \mathrm{mg}$ and $32 / 25 \mathrm{mg}$ in patients not optimally controlled with candesartan monotherapy. Blood Press Suppl. 2008;2:22-30.

38. Barrios V, Escobar C. Candesartan in the treatment of hypertension: what have we learnt in the last decade? Expert Opin Drug Saf. 2011;10(6):957-968. 
39. Barrios V, Boccanelli A, Ewald S, et al. Efficacy and tolerability of olmesartan medoxomil in patients with mild to moderate essential hypertension: the OLMEBEST study. Clin Drug Investig. 2007;27(8): $545-558$.

40. Sica D, Bakris GL, White WB, et al. Blood pressure lowering efficacy of the fixed dose combination of azilsartan and chlorthalidone: a factorial study. J Clin Hypertens (Greenwich). 2012;14(5):284-292.

41. Roush GC, Buddharaju V, Ernst ME, Holford TR. Chlorthalidone: mechanisms of action and effect on cardiovascular events. Curr Hypertens Rep. 2013;15(5):514-521.

42. SHEP Cooperative Research Group. Prevention of stroke by antihypertensive drug treatment in older persons with isolated systolic hypertension. Final results of the Systolic Hypertension in the Elderly Program (SHEP). JAMA. 1991;265(24):3255-3264.

43. Curb JD, Pressel SL, Cutler JA, et al. Effect of diuretic-based antihypertensive treatment on cardiovascular disease risk in older diabetic patients with isolated systolic hypertension. Systolic Hypertension in the Elderly Program Cooperative Research Group. JAMA. 1996;276(23): 1886-1892.

44. Kostis JB, Davis BR, Cutler J, et al. Prevention of heart failure by antihypertensive drug treatment in older persons with isolated systolic hypertension. SHEP Cooperative Research Group. JAMA. 1997;278(3):212-216.

45. Kostis JB, Cabrera J, Cheng JQ, et al. Association between chlorthalidone treatment of systolic hypertension and long-term survival. JAMA. 2011;306(23):2588-2593.

46. Oparil S, Davis BR, Cushman WC, et al; ALLHAT Collaborative Research Group. Mortality and morbidity during and after Antihypertensive and Lipid-Lowering Treatment to Prevent Heart Attack Trial: results by sex. Hypertension. 2013;61(5):977-986.

47. Rahman M, Pressel S, Davis BR, et al. Renal outcomes in high-risk hypertensive patients treated with an angiotensin-converting enzyme inhibitor or a calcium channel blocker vs a diuretic: a report from the Antihypertensive and Lipid-Lowering Treatment to Prevent Heart Attack Trial (ALLHAT). Arch Intern Med. 2005;165(8): 936-946.

48. Savage PJ, Pressel SL, Curb JD, et al. Influence of long-term, lowdose, diuretic-based, antihypertensive therapy on glucose, lipid, uric acid, and potassium levels in older men and women with isolated systolic hypertension: The Systolic Hypertension in the Elderly Program. SHEP Cooperative Research Group. Arch Intern Med. 1998;158: 741-751.

49. Dorsch MP, Gillespie BW, Erickson SR, Bleske BE, Weder AB. Chlorthalidone reduces cardiovascular events compared with hydrochlorothiazide: a retrospective cohort analysis. Hypertension. 2011;57(4):689-694.

50. Basile JN, Bloch MJ. Determining the relative antihypertensive potency and relative cardiovascular risk reduction associated with different thiazide and thiazide-type diuretics. J Clin Hypertens (Greenwich). 2013;15(6):359-361.

51. Ernst ME, Carter BL, Goerdt CJ, et al. Comparative antihypertensive effects of hydrochlorothiazide and chlorthalidone on ambulatory and office blood pressure. Hypertension. 2006;47(3):352-358.

52. Bakris GL, Sica D, White WB, et al. Antihypertensive efficacy of hydrochlorothiazide vs chlorthalidone combined with azilsartan medoxomil. Am J Med. 2012;125(12):1229.

53. Peterzan MA, Hardy R, Chaturvedi N, Hughes AD. Meta-analysis of dose-response relationships for hydrochlorothiazide, chlorthalidone, and bendroflumethiazide on blood pressure, serum potassium, and urate. Hypertension. 2012;59(6):1104-1109.

54. Ernst ME, Carter BL, Zheng S, Grimm RH Jr. Meta-analysis of doseresponse characteristics of hydrochlorothiazide and chlorthalidone: effects on systolic blood pressure and potassium. Am J Hypertens. 2010;23(4):440-446.

55. Matthews KA, Brenner MJ, Brenner AC. Evaluation of the efficacy and safety of a hydrochlorothiazide to chlorthalidone medication change in veterans with hypertension. Clin Ther. 2013;35(9):1423-1430.
56. Kwon BJ, Jang SW, Choi KY, et al. Comparison of the efficacy between hydrochlorothiazide and chlorthalidone on central aortic pressure when added on to candesartan in treatment-naïve patients of hypertension. Hypertens Res. 2013;36(1):79-84.

57. Ernst ME, Neaton JD, Grimm RH Jr, et al; Multiple Risk Factor Intervention Trial Research Group. Long-term effects of chlorthalidone versus hydrochlorothiazide on electrocardiographic left ventricular hypertrophy in the Multiple Risk Factor Intervention Trial. Hypertension. 2011;58(6):1001-1007.

58. Woodman R, Brown C, Lockette W. Chlorthalidone decreases platelet aggregation and vascular permeability and promotes angiogenesis. Hypertension. 2010;56(3):463-470.

59. Roush GC, Holford TR, Guddati AK. Chlorthalidone compared with hydrochlorothiazide in reducing cardiovascular events: systematic review and network meta-analyses. Hypertension. 2012;59(6): $1110-1117$.

60. Dhalla IA, Gomes T, Yao Z, Nagge J, et al. Chlorthalidone versus hydrochlorothiazide for the treatment of hypertension in older adults: a population-based cohort study. Ann Intern Med. 2013;158(6): $447-455$.

61. Roush GC, Buddharaju V, Ernst ME. Is chlorthalidone better than hydrochlorothiazide in reducing cardiovascular events in hypertensives? Curr Opin Cardiol. 2013;28(4):426-432.

62. National Institute for Health and Clinical Excellence. Hypertension. The clinical management of primary hypertension in adults. Aug 2011. Available from: http://www.nice.org.uk/guidance/CG127. Accessed April 3, 2014.

63. Mourad JJ, Waeber B, Zannad F, M, Duru G, Andréjak M; Investigators of the STRATHE Trial. Comparison of different therapeutic strategies in hypertension: a low-dose combination of perindopril/indapamide versus a sequential monotherapy or a stepped-care approach. J Hypertens. 2004;22(12):2379-2386.

64. Farsang C; Picasso Investigators. Blood pressure and metabolic efficacy of fixed-dose combination of perindopril and indapamide in everyday practice. Blood Press. 2013;22 Suppl 1:3-10.

65. Netchessova TA, Shepelkevich AP, Gorbat TV; on behalf of the NIKA Study Group. Efficacy of single-pill perindopril/indapamide in patients with hypertension and type 2 diabetes. High Blood Press Cardiovasc Prev. 2014;21(1):63-69.

66. Pella D. Efficacy and safety of treatment of hypertensive patients with fixed combination perindopril/indapamide up to $10 / 2.5 \mathrm{mg}$ : results of the FALCO FORTE programme. High Blood Press Cardiovasc Prev. 2011;18(3):107-113

67. Kang S, Wu YF, An N, Ren M. A systematic review and meta-analysis of the efficacy and safety of a fixed, low-dose perindopril-indapamide combination as first-line treatment of hypertension. Clin Ther. 2004;26(2):257-270.

68. ADVANCE Echocardiography Substudy Investigators; ADVANCE Collaborative Group. Effects of perindopril-indapamide on left ventricular diastolic function and mass in patients with type 2 diabetes: the ADVANCE Echocardiography Substudy. J Hypertens. 2011;29(7): 1439-1447.

69. Barrios V, Escobar C, Divison JA, Medialdea F. Low-dose fixed combination of perindopril plus indapamide in the diabetic hypertensive population. Expert Rev Cardiovasc Ther. 2008;6(8): 1063-1069.

70. Protasov KV, Sinkevich DA, Reshina IV, Zhizhko NV, Logovikova SI, Golubeva LV. [Vascular effects of perindopril arginine and indapamide fixed combination in patients with arterial hypertension]. Kardiologiia. 2012;52(9):8-14. Russian.

71. Neglia D, Fommei E, Varela-Carver A, et al. Perindopril and indapamide reverse coronary microvascular remodelling and improve flow in arterial hypertension. J Hypertens. 2011;29:364-372.

72. Hlavačková L, Vranková S, Janega $\mathrm{P}$, Pecháňová $\mathrm{O}$, Babál P. The effect of indapamide on development of myocardial hypertrophy and fibrosis in L-NAME-induced hypertension in rat. Physiol Res. 2011;60: $845-852$. 
73. PROGRESS Collaborative Group. Randomised trial of a perindoprilbased blood-pressure-lowering regimen among 6,105 individuals with previous stroke or transient ischaemic attack. Lancet. 2001;358(9287): 1033-1041.

74. Patel A; ADVANCE Collaborative Group. Effects of a fixed combination of perindopril and indapamide on macrovascular and microvascular outcomes in patients with type 2 diabetes mellitus (the ADVANCE trial): a randomised controlled trial. Lancet. 2007;370(9590):829-840.

75. Ninomiya T, Zoungas S, Neal B, et al; ADVANCE Collaborative Group. Efficacy and safety of routine blood pressure lowering in older patients with diabetes: results from the ADVANCE trial. J Hypertens. 2010;28(6):1141-1149.

76. Heerspink HJ, Ninomiya T, Perkovic V, et al; ADVANCE Collaborative Group. Effects of a fixed combination of perindopril and indapamide in patients with type 2 diabetes and chronic kidney disease. Eur Heart J. 2010;31(23):2888-2896.

77. Beckett NS, Peters R, Fletcher AE, et al. HYVET Study Group. Treatment of hypertension in patients 80 years of age or older. $N$ Engl J Med. 2008;358(18):1887-1898.

78. Beckett N, Peters R, Tuomilehto J, et al; HYVET Study Group. Immediate and late benefits of treating very elderly people with hypertension: results from active treatment extension to Hypertension in the Very Elderly randomised controlled trial. BMJ. 2011;344:d7541.

79. González-Juanatey JR, Cordero A. Benefits of delapril in hypertensive patients along the cardiovascular continuum. Expert Rev Cardiovasc Ther. 2013;11(3):271-281.

80. Rosei EA, Rizzoni D; DIMS II (Delapril-Indapamide Multicenter Study II). Evaluation of the efficacy and tolerability of the combination delapril plus indapamide in the treatment of mild to moderate essential hypertension: a randomised, multicentre, controlled study. J Hum Hypertens. 2003;17(2):139-146.

81. Acanfora D, Lowenthal DT, Furgi G, et al. Effects of delapril in combination with indapamide on blood pressure and left ventricular mass in elderly hypertensive patients. Am J Ther. 1998;5(1):17-23.

82. Acanfora D, Lowenthal DT, Furgi G, et al. The effects of delapril in combination with indapamide on glomerular filtration rate in elderly hypertensive patients. Am J Ther. 1997;4(11-12):405-408.

83. Leonetti G, Emeriau JP, Knauf H, Pujadas JO, Calvo-Gomez C, Abate G; European Study Investigators. Evaluation of long-term efficacy and acceptability of indapamide SR in elderly hypertensive patients. Curr Med Res Opin. 2005;21(1):37-46.

84. Nedogoda SV, Marchenko IV, Chaliabi TA, Tsoma VV, Brel UA, Prokhorova EA. [Comparative efficacy of fixed dose combinations of perindopril with indapamide and captopril with hydrochlorothiazide in patients with high risk hypertension]. Kardiologiia. 2005;45(11):24-26. Russian.

85. Karpov IA. [The FORTISSIMO program: advantages of fixed full dose combination of perindopril arginine and indapamide in the treatment of poorly controlled arterial hypertension]. Kardiologiia. 2013;53(3):37-43. Russian.
86. Cremonesi G, Cavalieri L, Cikes I, et al. Fixed combinations of delapril plus indapamide vs fosinopril plus hydrochlorothiazide in mild to moderate essential hypertension. Adv Ther. 2002;19(3):129-137.

87. Circelli M, Nicolini G, Egan CG, Cremonesi G. Efficacy and safety of delapril/indapamide compared to different ACE-inhibitor/ hydrochlorothiazide combinations: a meta-analysis. Int J Gen Med. 2012;5:725-734.

88. Semenkin AA, Zhivilova LA, Golevtsova ZS, et al. [Comparative assessment of hypotensive, metabolic, and endothelial effects of indapamide-retard and hydrochlorothiazide in patients with essential hypertension]. Kardiologiia. 2006;46(5):35-39. Russian.

89. Islam MZ, Rahman MS. Comparative study of hydrochlorothiazide and indapamide on the anti-atherogenic potential of losartan in cholesterol fed rat. Bangladesh Med Res Counc Bull. 2010;36(1):14-19.

90. Chobanian AV, Bakris GL, Black HR, et al. National Heart, Lung, and Blood Institute Joint National Committee on Prevention, Detection, Evaluation, and Treatment of High Blood Pressure; National High Blood Pressure Education Program Coordinating Committee. The seventh report of the Joint National Committee on Prevention, Detection, Evaluation, and Treatment of High Blood Pressure: the JNC 7 report. JAMA. 2003;289(19):2560-2572.

91. Carter BL. Guidelines for use of diuretics: a view from a member of JNC 7. J Clin Hypertens (Greenwich). 2012;14(5):273-276.

92. Kountz DS, Goldman A, Mikhail J, Ezer M. Chlorthalidone: the forgotten diuretic. Postgrad Med. 2012;124(1):60-66.

93. Waeber B, Rotaru C, Feihl F. Position of indapamide, a diuretic with vasorelaxant activities, in antihypertensive therapy. Expert Opin Pharmacother. 2012;13(10):1515-1526.

94. Padilla MC, Armas-Hernández MJ, Hernández RH, Israili ZH, Valasco M. Update of diuretics in the treatment of hypertension. Am J Ther. 2007;14(2):154-160.

95. Pitt B, Zannad F, Remme WJ, et al. The effect of spironolactone on morbidity and mortality in patients with severe heart failure. Randomized Aldactone Evaluation Study Investigators. NEngl J Med. 1999;341(10): 709-717.

96. Pitt B, Remme W, Zannad F, et al. Eplerenone, a selective aldosterone blocker, in patients with left ventricular dysfunction after myocardial infarction. N Engl J Med. 2003;348(14):1309-1321.

97. Zannad F, McMurray JJ, Krum H, et al. Eplerenone in patients with systolic heart failure and mild symptoms. $N$ Engl J Med. 2011;364(1):11-21.

98. Ernst ME, Lund BC. Renewed interest in chlorthalidone: evidence from the Veterans Health Administration. J Clin Hypertens (Greenwich). 2010;12(12):927-934.
Integrated Blood Pressure Control

\section{Publish your work in this journal}

Integrated Blood Pressure Control is an international, peer-reviewed open-access journal focusing on the integrated approach to managing hypertension and risk reduction. Treating the patient and comorbidities together with diet and lifestyle modification and optimizing healthcare resources through a multidisciplinary team approach constitute key

\section{Dovepress}

features of the journal. This journal is indexed on American Chemical Society's Chemical Abstracts Service (CAS). The manuscript management system is completely online and includes a very quick and fair peerreview system, which is all easy to use. Visit http://www.dovepress.com/ testimonials.php to read real quotes from published authors. 